\title{
AVALIAÇÃO DA INFLUÊNCIA DO DESGASTE DA CALHA ROTATIVA NA DISTRIBUIÇÃO DE CARGA DO ALTO FORNO*
}

\author{
André Wulff Hirano ${ }^{1}$ \\ Bruno Pinheiro da Silva ${ }^{2}$ \\ Bruno Ribeiro de Miranda Lima ${ }^{3}$ \\ Rodrigo Magalhães de Carvalho ${ }^{4}$
}

\section{Resumo}

Controlar a distribuição de carga do Alto Forno é fundamental para o controle de processo, e através de sua otimização, dentre as mais variadas configurações operacionais, busca-se lograr da estabilidade do processo e aproveitamento do gás no interior do reator. Para tal, utiliza-se um sistema de carregamento, sendo o mais usado na atualidade o do tipo Bell Less Top com calha rotativa. Durante o carregamento do forno as partículas passam pela calha rotativa, resultando em abrasão dos elementos de desgaste que por sua vez, altera a geometria da mesma, gerando alterações na trajetória das partículas carregadas e a mudança de trajetória pode perturbar a marcha do Alto Forno. Nesse contexto, a boa condição da calha passa a ser um fator essencial para a manutenção da estabilidade operacional. $O$ presente trabalho, aplica o método dos elementos discretos (DEM) para caracterizar os efeitos do desgaste da calha na trajetória do material descarregado, podendo assim avaliar melhor os distúrbios na estabilidade do Alto Forno, e com isso a indicar o melhor momento para troca da calha.

Palavras-chave: DEM; Alto Forno; Distribuição de carga; Calha rotativa.

\section{EVALUATION THE INFLUENCE OF THE WEAR OF THE ROTATING CHUTE IN THE BURDEN DISTRIBUTION IN BLAST FURNACE}

\begin{abstract}
The burden distribution in the blast furnace is the fundamental step for process control, and through its optimization, among the most varied operational configurations, it is sought to achieve the process stability and the best use of the gas inside the reactor. For this, the charging system is used, being the most used at the present time the Bell Less Top with rotating chute. In this context, the good condition of the chute becomes an essential factor for the maintenance of the operational stability, and its wear can alter the trajectory of the particles, causing disturbances in the blast furnace. This work, through the discrete elements method (DEM), seeks to characterize the wear effects of the chute in the trajectory of the material, thus being able to better evaluate the disturbances in the stability of the blast furnace, and with that to indicate the best moment for changing the rotating chute.

Keywords: DEM; Blast Furnace; Burden distribution; Rotating chute.

\footnotetext{
Engenheiro Metalúrgico, Coordenador de Unidade Técnica, CSA, Rio de Janeiro, RJ, Brasil.

Engenheiro Químico, Engenheiro de Processo, CSA, Rio de Janeiro, RJ, Brasil.

Engenheiro de Materiais, BRFoods, Rio de Janeiro, RJ, Brasil.

Engenheiro Químico, Professor Adjunto, Universidade Federal do Rio de Janeiro, RJ, Brasil.
} 


\section{INTRODUÇÃO}

Os primeiros Altos Fornos conhecidos para a produção de ferro gusa, então chamados de flussöfen, datam do século XV [1]. Desde a construção os altos fornos evoluíram consideravelmente em tamanho durante o século XX. No início do século $\mathrm{XX}$, os altos fornos tinham um diâmetro de cadinho de 4 a 5 metros e produziam próximo de 100.000 toneladas de metal quente por ano, a maioria a partir de minério calibrado e coque. Ao final do século XX, os maiores altos fornos tinham de 14 a 15 metros de diâmetro do cadinho e estavam produzindo de 3 a 4 milhões de toneladas por ano [2]. Porém mesmo com todo o desenvolvimento do último século, um dos melhores modelos que explica a operação do forno é um modelo tipo "caixa preta" chamado diagrama de Rist. O diagrama de Rist é um modelo que incorpora as principais características de operação de um Alto Forno, ilustrando soluções para vários problemas através de balanços de massa e de calor em estado estacionário, relacionando o grau de oxidação do gás e carga [3]. Embora a operação dos Altos Fornos ainda esteja amplamente baseada na experiência de operação, os modelos matemáticos cada vez mais se tornam uma ferramenta importante para otimização do processo e a utilização de técnicas discretas, como o Método dos Elementos Discretos (DEM), podem mudar a forma de modelar e analisar o alto forno. O DEM amplia a capacidade de prever o comportamento da população das partículas através das suas contribuições individuais, permitindo a análise de distúrbios em regiões especificas, onde não se tem a capacidade de medição, quer seja pelo custo ou natureza da região.

Dessa forma, alguns trabalhos usando DEM começaram a ser desenvolvido afim de predizer de forma mais realista o comportamento das partículas durante a distribuição no alto forno, como feito por Tamoghna Mitra [4]. O DEM também tem uma elevada capacidade de previsão em situação onde o desgaste do equipamento influencia o processo, dessa forma é possível avaliar a mudança no comportamento do escoamento das partículas com o desgaste da calha rotativa observado na Figura 1 , onde o escoamento em elevada velocidade gerou um desgaste acentuado próximo a ponta da calha após aproximadamente um ano de uso.

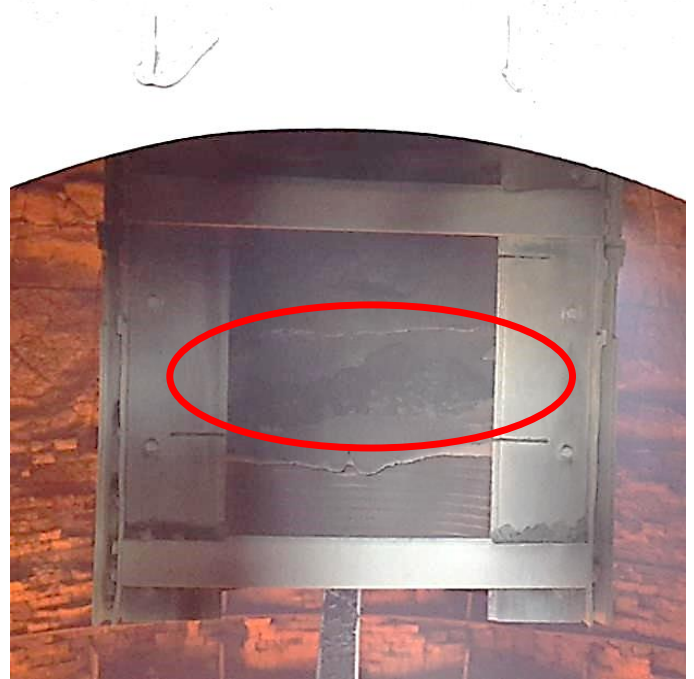

Figura 1 - Desgaste observado da calha. 
Dentre toda a gama de possibilidades de análise no Alto Forno, o presente trabalho tem como objetivo avaliar o efeito de uma situação muito comum, onde verifica-se o impacto de um desgaste especifico da calha rotativa na distribuição da carga no forno para a decisão de troca.

Com as propriedades das partículas, geometria, modelo de força de contato, tempo de integração e movimentação da geometria definidos foi possível realizar as simulações que integram a aplicação da segunda Lei de Newton e a Lei de Força, determinando o deslocamento de cada partícula individual, bem como resultado das colisões entre partícula-partícula e partícula-fronteiras, conforme esquema representado na Figura 2, da seguinte forma:

- Calcula das interações das colisões entre as partículas usando um modelo de contato.

- Integra no domínio do tempo o sistema de equações de movimento e determina as posições e velocidades das partículas individuais.

- Computa as quantidades de transporte relevantes, propriedades da população e analisa a evolução da estrutura, determina as novas colisões e atualiza o balanço de forças.

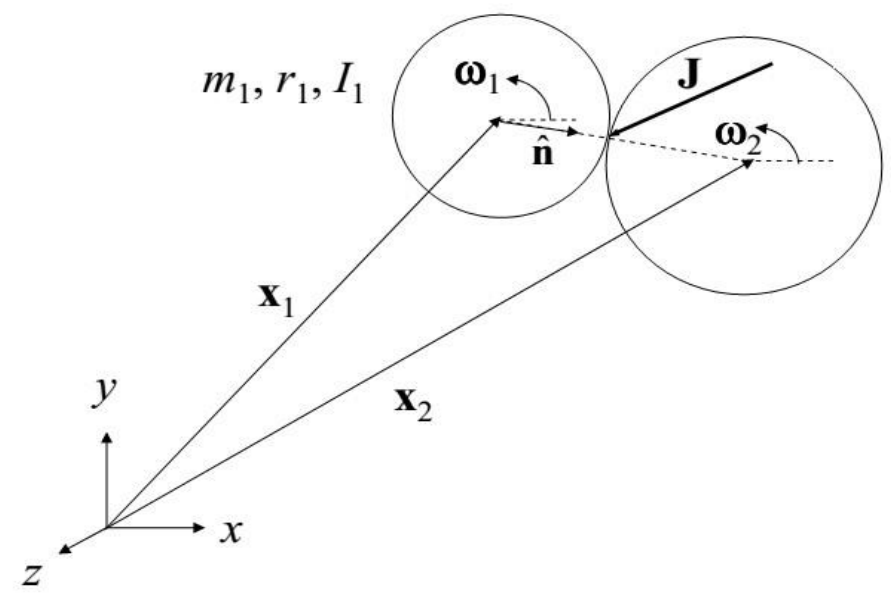

Figura 2 - Modelo de colisão para esferas.

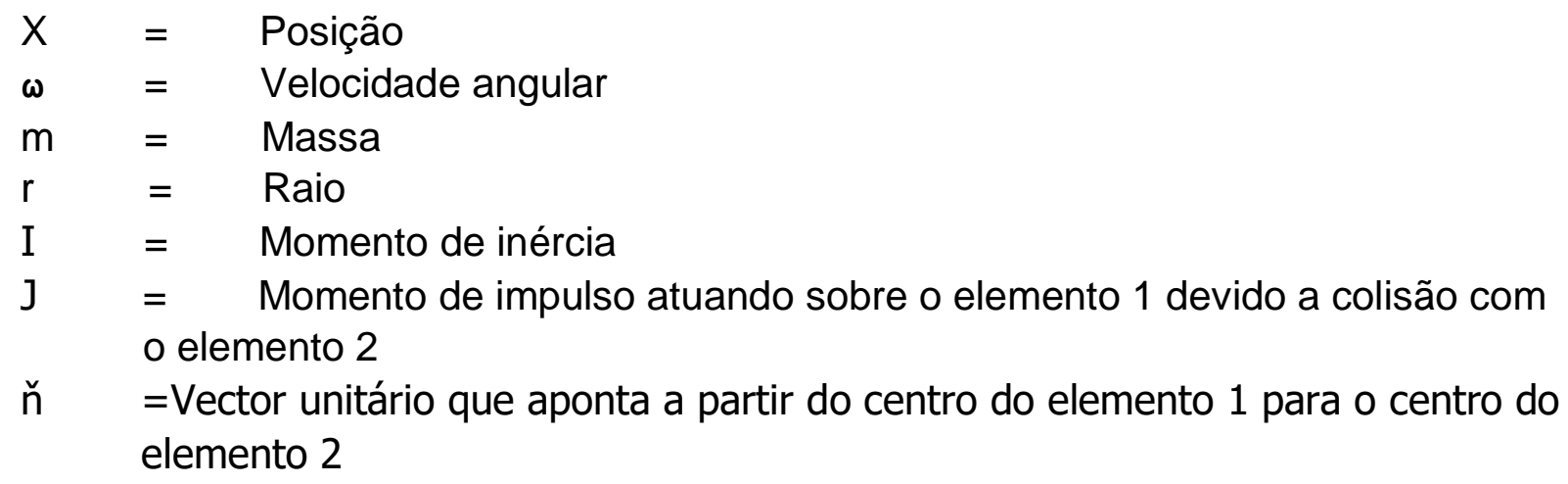


Entretanto, Marigo [5] cita alguns fatores que limitam a utilização do DEM em relação ao tempo e capacidade de processamento computacional, como o número de partículas no sistema, tamanho, propriedades dos materiais e tempo total de simulação.

\section{MATERIAIS E MÉTODOS}

\subsection{Construção da geometria tridimensional para as simulações.}

Afim de reproduzir fielmente o ambiente encontrado pelas partículas carregada no alto forno, implementou-se a geometria das partes relevantes de um alto forno localizado na cidade do Rio de Janeiro, como o hopper de alimentação, a calha rotativa bem como as paredes internas do forno. A ferramenta CAD utilizada foi o Sketchup versão 8 (Trimple,2015). O topo do forno simulado e suas características de projeto e operacionais podem ser observadas na Tabela 1.

Tabela 1 - Dados de projeto do Alto Forno.

\begin{tabular}{|l|c|}
\hline \multicolumn{2}{|c|}{ DADOS DE PROJETO DOS ALTOS FORNOS } \\
\hline \hline Produção & 5,3 milhões / ano \\
\hline Produção / dia/ AF & 7.500 toneladas \\
\hline Produtividade & 2.28 \\
\hline Indice de disponibilidade & $>97 \%$ \\
\hline Coke Rate & $350 \mathrm{~kg} / \mathrm{thm}$ \\
\hline PCR & $160 \mathrm{~kg} / \mathrm{thm}$ \\
\hline Fuel rate & $510 \mathrm{~kg} / \mathrm{thm}$ \\
\hline Volume Interno & $3.284 \mathrm{~m}{ }^{3}$ \\
\hline Volume de trabalho & $2.775 \mathrm{~m}$ \\
\hline Diâmetro do cadinho & $12.0 \mathrm{~m}$ \\
\hline Diâmetro da goela (Throat) & $8.5 \mathrm{~m}$ \\
\hline \multicolumn{1}{|c|}{ REGENERADORES } \\
\hline \hline Regeneradores & 3 \\
\hline Temperatura sopro & $1250^{\circ} \mathrm{C}$ \\
\hline Superfície de aquecimento & $54355 \mathrm{~m} 2$ \\
\hline Temperatura do domo & $1485^{\circ} \mathrm{C}$ \\
\hline Temperatura da Chaminé & $450^{\circ} \mathrm{C}$ \\
\hline Poder calorífico gás de topo & $66.820 \mathrm{~m} 3 / \mathrm{h}$ \\
\hline Taxa de gas de topo por regenerador & $108.049 \mathrm{~m} 3 / \mathrm{h}$ \\
\hline Taxa de ar para combustão por regenerador & $\mathrm{a} 3600 \mathrm{kj} / \mathrm{m} 3$ \\
\hline
\end{tabular}

\begin{tabular}{|l|c|}
\hline \multicolumn{2}{|c|}{ TOPO DO FORNO } \\
\hline \multicolumn{2}{|c|}{ Bell less, Paul Wurth System } \\
\hline Quantidade de Silos & 2 \\
\hline Capacidade dos silos & $70 \mathrm{~m} 3$ - cada \\
\hline Pressão de topo & 2,5 bar \\
\hline
\end{tabular}




\begin{tabular}{|l|c|}
\hline \multicolumn{1}{|c|}{ Temperatura gás de topo } & $150-200^{\circ} \mathrm{C}$ \\
\hline \multicolumn{1}{|c|}{ INJECÃO DE CARVÃO PULVERIZADO } \\
\hline \hline Taxa injeção de carvão (coal) & $50 \mathrm{t} / \mathrm{h}-160 \mathrm{~kg} /$ ton de gusa \\
\hline Taxa injeção de carvão (coal) max. & $220 \mathrm{~kg} /$ ton de gusa \\
\hline \hline Quantidade de Silos / capacidade & $1 \times 1200 \mathrm{~m} 3$ \\
\hline Quantidade Vaso de injeção / capacidade & 2 para cada forno $-30 \mathrm{~m} 3$ \\
\hline
\end{tabular}

Para a simulação, foi criado o modelo da calha 3D em escala real a partir de um modelo 2D e um modelo de calha desgastada através da observação durante a operação, para isso, foi usado a ferramenta SketchUp 2017.

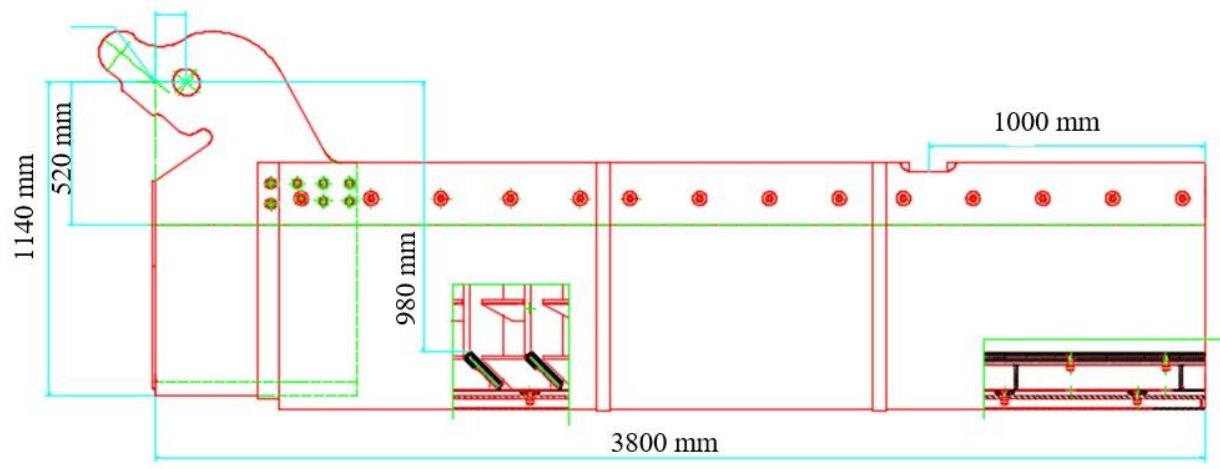

Figura 3 - Modelo da calha 2D

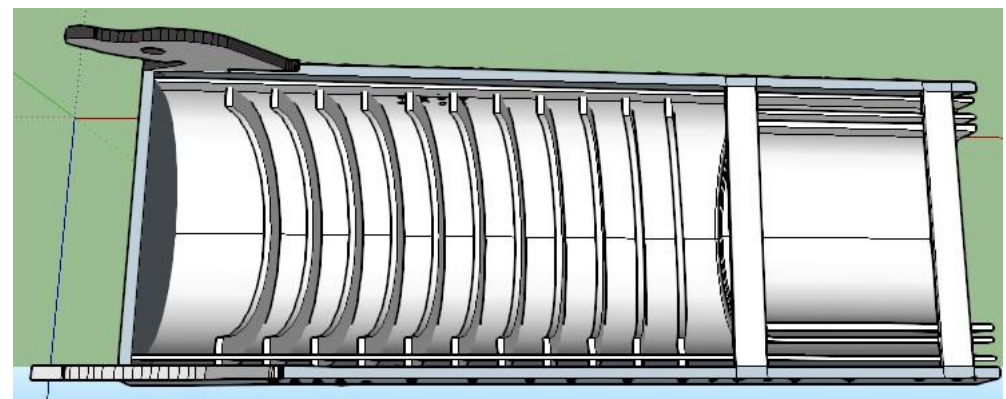

Figura 4 - Modelo da calha 3D

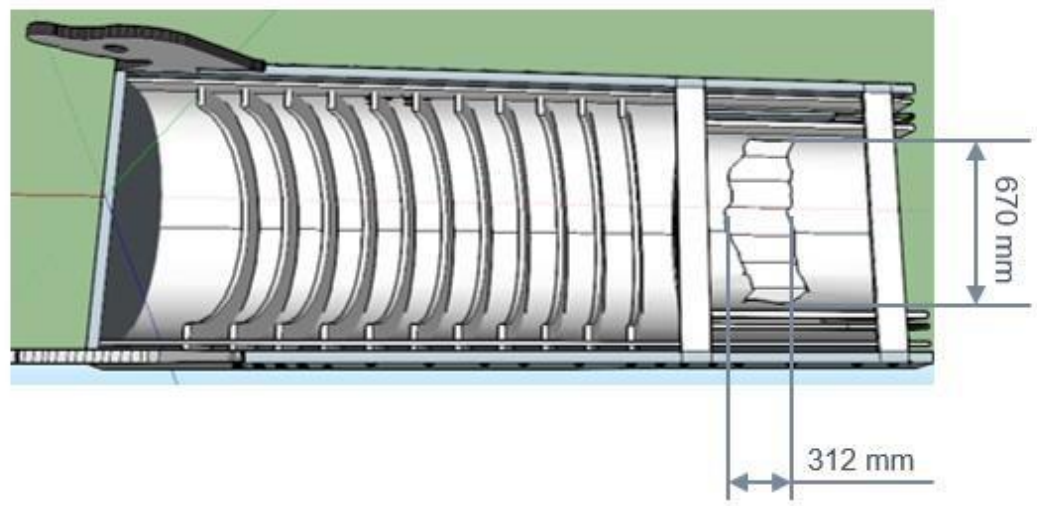

Figura 5 - Modelo da calha 3D desgastada. 


\subsection{Simulação pelo Método dos Elementos Discretos}

Para a realização das simulações foi utilizado o software EDEM® [6] versão EDEM_2.7.1. Afim de reduzir a demanda computacional, optou-se por simular o fluxo de partículas a partir do ponto de chegada na calha rotativa. Desta forma, os efeitos do empilhamento do material recém alimentado no topo da carga do forno não foram objeto de estudo desse trabalho.

\subsubsection{Modelo e parâmetros de contato}

Para uma boa simulação é necessário ajustar um conjunto de parâmetros adequados para uma boa resposta do simulador, dessa forma, o primeiro passo é definir um modelo de forças de contato, no caso da simulação da calha, foi definido o modelo de forças de contato Hertz-Mindlin sem escorregamento, pois se trata de um modelo de contato não linear do tipo esfera macia, sendo o ideal para o sistema. O modelo de Hertz-Mindlin é considerado um modelo padrão na simulação de aplicações em processos da indústria mineral e siderúrgica e considera um componente de amortecimento na força normal e tangencial que tem a relação entre o coeficiente de amortecimento e o coeficiente de restituição como descritos por TSUJl et al. [6]. A força de atrito tangencial segue a lei de Coulomb como exemplificado por CUNDALL e STRACK [7], sendo depende apenas do coeficiente de Poisson e do módulo de cisalhamento.

Considerando a carga como coque metalúrgico, com distribuição granulométrica entre $35 \mathrm{~mm}$ e $100 \mathrm{~mm}$ e vazão de distribuição típica na faixa de $0,3 \mathrm{~m}^{3} / \mathrm{s}$, os parâmetros foram escolhidos de forma criteriosa visando a reprodução do comportamento físico d o sistema, sendo determinado anteriormente por Ribeiro [8].

Tabela 1: Parâmetros de contato dos materiais

\begin{tabular}{lcc}
\hline Parâmetros & Coque & Aço \\
\hline Coeficiente de Poisson & 0,25 & 0,25 \\
Módulo de cisalhamento $(\mathrm{Pa})$ & $1 \mathrm{E}+08$ & $1 \mathrm{E}+08$ \\
Densidade $\left(\mathrm{kg} / \mathrm{m}^{3}\right)$ & 1180 & 7800 \\
\hline \hline
\end{tabular}

Tabela 2: Parâmetros de contato entre as partículas

\begin{tabular}{lcc}
\hline Material & Coque-Coque & Coque-Aço \\
\hline Coeficiente de restituição & 0,4 & 0,4 \\
Coeficiente de atrito estático & 0,3 & 0,45 \\
Coeficiente de rolamento & 0,3 & 0,37 \\
\hline \hline
\end{tabular}




\subsubsection{Estratégia de simulação}

No presente trabalho, as simulações focaram na trajetória do material carregado. Dessa forma o volume de controle foi definido no início da calha como ponto zero e o final da trajetória como $6,7 \mathrm{~m}$. Sendo assim, foi simulado o stock line de trabalho do forno. Para as análises realizadas, foi definido o tempo inicial de 7,5 s para a avaliação da trajetória, pois nesse instante observa-se que o sistema está em regime permanente. O tempo total de simulação foi de $22,5 \mathrm{~s}$, sendo equivalente a 3 voltas da calha e utilizando a inclinação de $37^{\circ}$. A velocidade de rotação da calha foi definida de acordo com o projeto, $8 \mathrm{rpm}$. A força de campo definida foi o campo gravitacional em $9,81 \mathrm{~m} / \mathrm{s}^{2}$ não sendo levando em conta as forças de arraste pelo gás no topo do reator.

\section{RESULTADOS E DISCUSSÃO}

Foram realizadas simulações com a calha de acordo com o projeto (nova) e a calha com o desgaste após aproximadamente 1 ano de operação, durante as simulações foram verificadas as diferenças na trajetória da calha nova e da danificada com a curva de distribuição equivalente do projeto, assim pode-se checar a aderência da simulação ao projeto e o desvio da trajetória para o cenário em que a calha se encontra desgastada, como pode ser observado inicialmente na Figura 60 desvio causado pelo desgaste da calha onde cada partícula é representada pelo seu respectivo vetor velocidade e colorida em função da magnitude da velocidade.

Calha Rotativa Regular

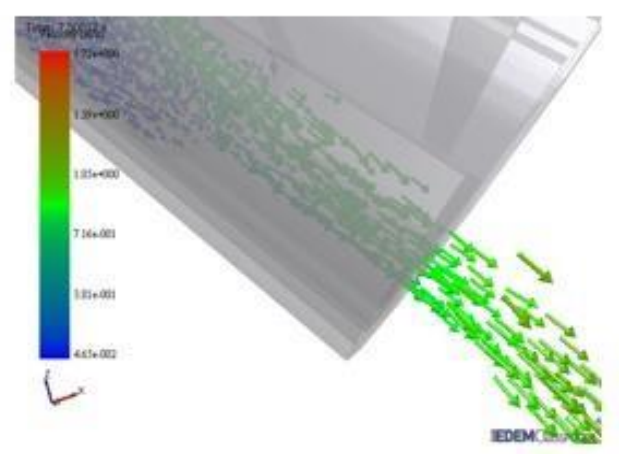

Calha Rotativa Danificada

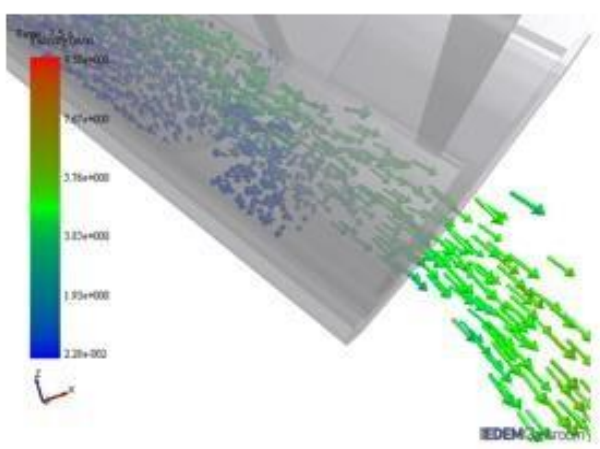

Figura 6 - Vista lateral da simulação para os dois casos avaliados: calha nova (esquerda) e calha danificada (direita). As partículas de coque pelos seus vetores velocidade na forma de seta.

A análise das trajetórias obtidas com as simulações em DEM permite confrontá-las com a curva de projeto. Esta comparação é apresentada na Figura 7 que mostra a linha contínua sendo a curva de projeto e os demais pontos, aqueles obtidos pelas simulações. 
Analisando a resposta para o caso com a calha nova, foi verificado uma boa aderência do deslocamento das partículas à mesma, com a trajetória praticamente equivalente à curva de projeto. Para o caso da calha danificada, como esperado, a simulação mostrou um recuo de $64 \mathrm{~cm}$ na trajetória do fluxo de partículas descarregadas e um espalhamento que aumentou a espessura do leque em $90 \%$, que como consequência principal, afetará o empilhamento das partículas
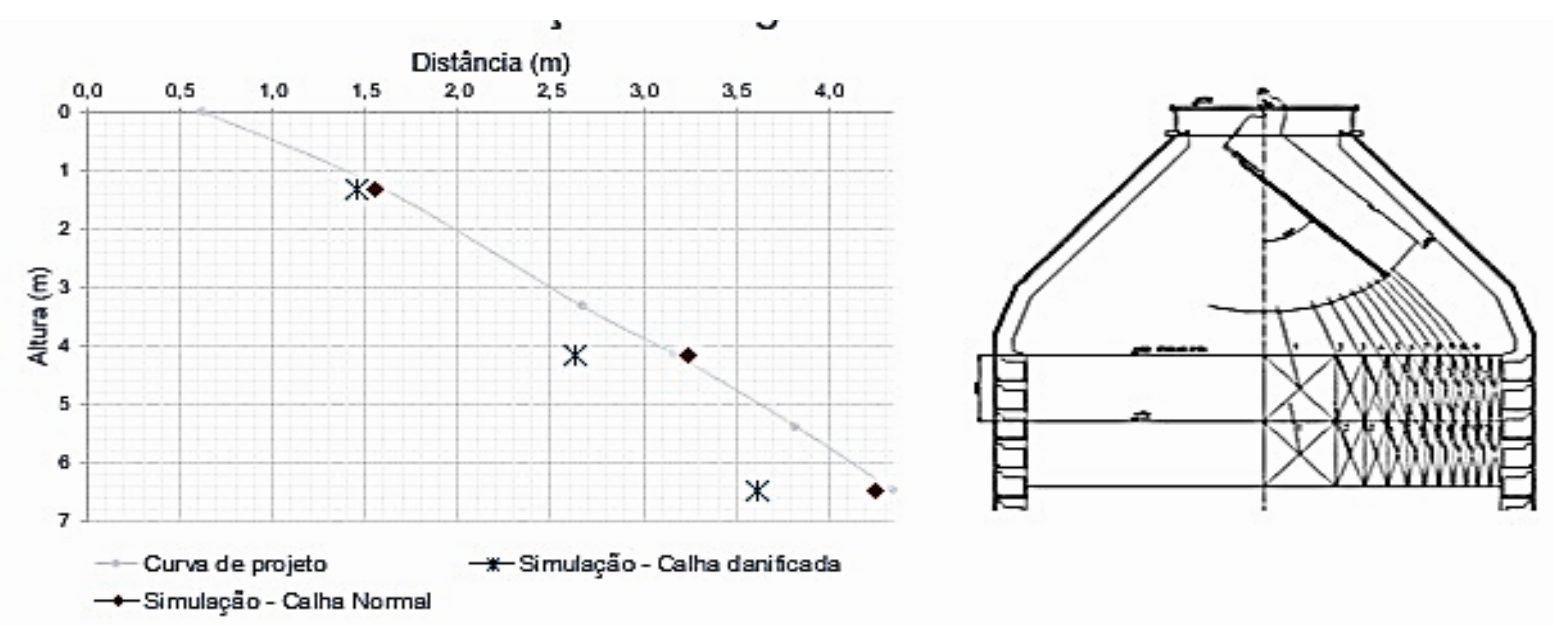

Figura 7 - Curva de distribuição de carga

Assim pode-se entender melhor a influencia no processo, onde espera-se que com o desgaste da calha ocorra uma abertura da marcha periférica no reator e em caso de empilhamento do coque inadequado pode gerar uma perda de rendimento do gás no topo devido a maior instabilidade do fluxo gasoso.

Adicionalmente, foi possível analisar com o DEM propriedades individuais das partículas simuladas, fato que não é possível de ser realizado em um sistema real. Analisando-se a evolução da energia cinética total das partículas no sistema, verificou-se inicialmente que há um crescimento dessa energia, dada pela entrada das partículas no sistema e sua aceleração devido à ação da força gravitacional. Confrontando os resultados para as duas calhas, verifica-se na figura 8 que a simulação com a calha já desgastada impõe uma redução de $5 \%$ na energia cinética total do sistema simulado. Esse fenômeno pode ser observado devido os choques calha-partícula e calha-partícula-partícula, pois mesmo que todas as partículas não se choquem diretamente com a região desgastada, algumas o percebem de forma indireta através do contato com partículas que desaceleraram ao colidirem na região desgastada. 


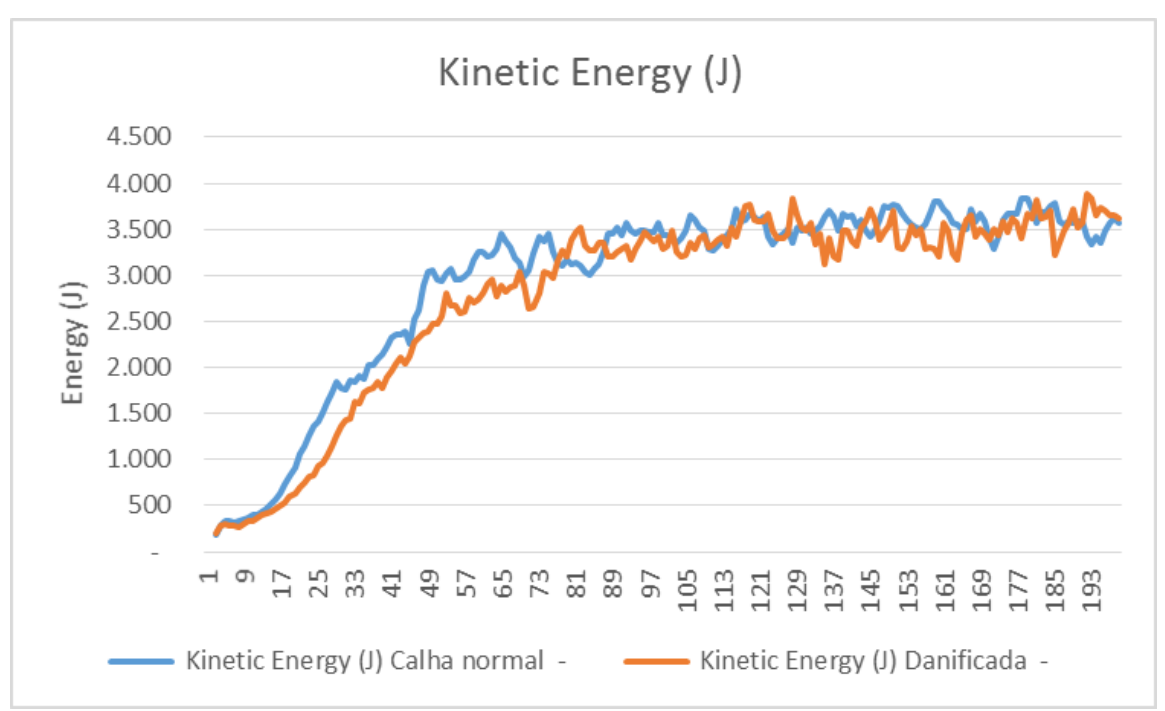

Figura 8 - Variação da energia cinética do sistema

Outra variável analisada foi a velocidade apresentada pelas partículas no limite do volume de controle, ou seja, quando estas atingem o topo da carga. Podese observar que nem todas as partículas sentem a presença do dano da calha. Já que não foi encontrado variação na velocidade final da partícula mais rápida (Figura 9), assim explica-se o maior espalhamento das partículas e a contração média da trajetória devido a energia cinética média que foi $5 \%$ menor.

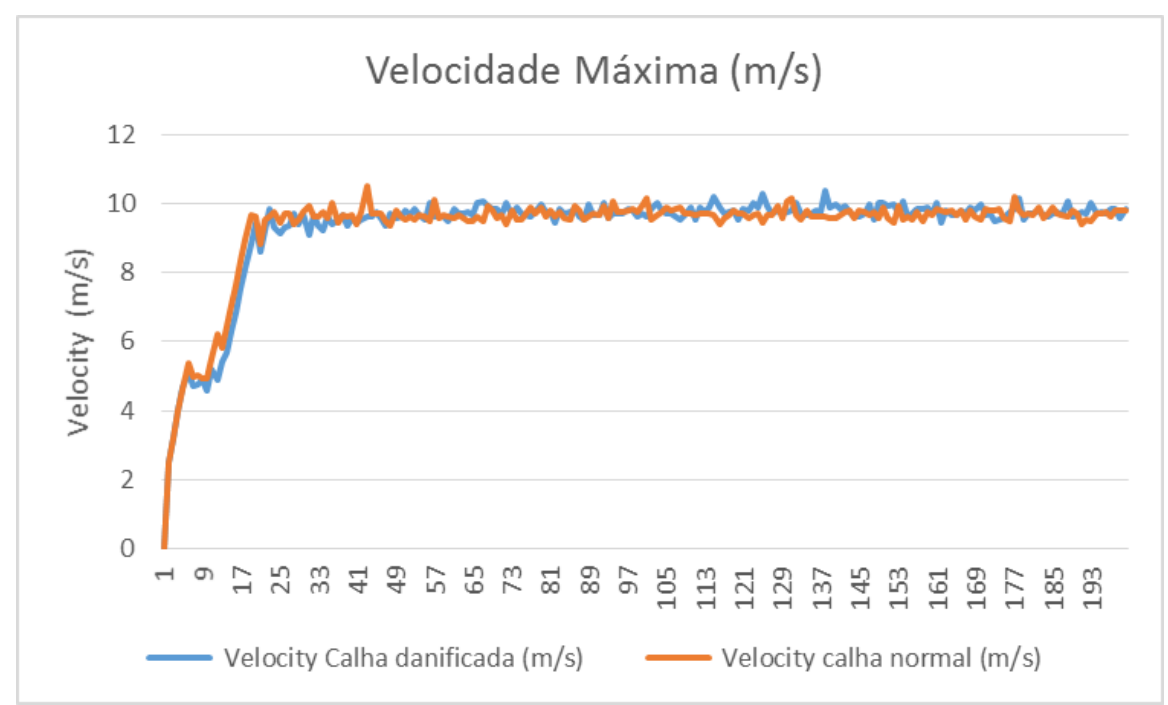

Figura 9 - Variação da velocidade máxima. 


\section{CONCLUSÕES}

- Foi possível verificar a aplicabilidade do método dos elementos discretos para análise da distribuição do alto forno.

- Com as simulações simples, foi possível verificar uma boa representatividade das curvas de distribuição do projeto através do método dos elementos discretos.

- Ao avaliar a distribuição com a calha desgastada, foi verificado que ela impacta na trajetória do material, causando para o desgaste simulado um aumento no tamanho do leque de $90 \%$ e uma contração na trajetória do material de $64 \mathrm{~cm}$.

Sugere-se para trabalhos futuros:

- Simulação da descarga completa avaliando os efeitos no empilhamento.

- Avaliação de outras configurações de desgaste, de forma a determinar o desgaste máximo que influência no Sistema.

- Desenvolvimento de outras geometrias e espessuras de chapas de desgaste, par reduzir o efeito na trajetória do material. 


\section{REFERÊNCIAS}

1. RIZZO, E. M., Processo de fabricação de ferro gusa em alto-forno / Ernandes Marcos da Silveira Rizzo. São Paulo, Associação Brasileira de Metalurgia, Materiais e Mineração, 2009.

2. GEERDES, M., VAN DER VLIET, C., TOXOPEUS, Second Edition 2009. Modern Blast Furnace Ironmaking an Introduction, Amsterdam.

3. FUJIHARA, F. CUNHA, F. DEFENDI, G. GUSHIKEN, J. SILVA, M. Revisitando o diagram de Rist, ABM, Florianópolis SC, 2005.

4. Mitra, T. Modeling of Burden Distribution in the Blast Furnace. Doctor of Technology Thesis, Faculty of Science and Engineering, Åbo Akademi University, Finland, 2016.

5. MARIGO, M. Discrete Element Method Modelling of Complex Granular Motion in Mixing Vessels: Evaluation and Validation. Tese de doutorado, University of Birmingham, 2012.

6. TSUJI, Y; TANAKA, T; ISHIDA, T. Lagrangian numerical simulation of plug flow of cohesionless particles in a horizontal pipe. Powder Technology, v. 71, n. 3, p. 239-250, 1992

7. CUNDALL, P.A., STRACK, O.D.L., 1979. A discrete numerical model for granular assemblies. Geotechique 29, 47-65.

8. RIBEIRO, B. CARVALHO, R. Simulação do carregamento do alto forno dotado de um sistema bell less top usando o método de elementos discretos (DEM), Rio de janeiro, UFRJ, 2016.

9. BOECHAT, F. CARVALHO, R. Influência do tamanho de partículas para simulação pelo método dos elementos discretos em avaliação de um misturador horizontal, UFRJ/COPPE/Programa de engenharia Metalúrgica e de Materiais. Rio de Janeiro, 2015.

10. DEM Solutions. EDEM 2.6 Theory Reference Guide, Manual teorico do EDEM, Edimburgo, 2014. 